\title{
A NOTE ON DUPUY'S QJM AND NEW SQUARE LAW
}

\author{
GERHARD GELDENHUYS and ELMARIE BOTHA \\ Department of Applied Mathematics \\ University of Stellenbosch \\ 7600 Stellenbosch \\ SOUTH AFRICA
}

\begin{abstract}
:
T.N. Dupuy has developed various operations research models in an attempt to quantify lessons that can be learned from military history. We discuss two of his models, the Quantified Judgment Model (QJM), and the "new square law". The QJM was developed by Dupuy for the analysis of military operations. We point out mathematical discrepancies in a part of the model and make suggestions to remove these discrepancies. Dupuy's new square law is an attempt to modify the well-known Lanchester equations for aimed fire, taking into account some results that were obtained in the QJM. We show that the new square law cannot be accepted as a valid mathematical model of combat attrition.
\end{abstract}

\section{INTRODUCTION}

Although a wide spectrum of variations of the well-known Lanchester equations for combat attrition has evolved over the years, there still are serious doubts about the validity of the equations for actual combat. The analyses by military historians of particular battles can be of great value to explain scenarios, strategies and tactics and to extract battle data with which the validity of theories may be tested. Unfortunately historians do not necessarily describe the data which would be required for mathematical modelling. Even if they do give data, this is not always provided in a format which is conducive to effective modelling. 
T.N. Dupuy, a retired colonel of the United States Army, is a well-known military historian who has researched and published extensively on the quantitative aspects of military battles $[1,3,4]$. We discuss two mathematical models found in his work, the Quantified Judgment Model (OJM) for the analysis of military operations [1], and his "new square law" [3] which attempts to improve on the original Lanchester equations in the light of certain results from the Q.JM.

\section{ASPECTS OF THE QUANTIFIED JUDGMENT METHOD}

Dupuy's point of departure in the development of the QJM is commendable: military history is very relevant to modern warfare, provided that the analyst uses a fresh approach in transforming the historical combat data into "a coherent, consistent, quantitative theory of combat and combat relationships" [1]. With this goal in mind he has analysed a large number of military battles quantitatively and qualitatively. In his quantitative analyses he uses many variables, but for our purposes it is sufficient to concentrate on only a few of these.

Consider a battle between two sides, Red and Blue, and use subscripts $r$ and $b$ where necessary to distinguish between the respective sides. $P$ is the combat power of a force and $S$ the force strength, while $V$ 'denotes environmental and operational force effects. The actual result of a battle is denoted by $R$, and is calculated by taking into account a mission factor, spatial effectiveness and casuaity effectiveness. Implicit in Dupuy's work is the assumption that battie outcomes are relative in the sense that a side A might perform very differently against a side $B$ than against a side $C$, even though the strength and preparation of $B$ and $C$ for the two encounters are precisely the same, that is, even though its values for $S$ and $V$ are the same in the two cases. In view of this implicit assumption we make a slight change in Dupuy's notation by using, for example, the subscript $b / r$ to indicate a calculation of Blue with respect to Red. In the QJM the theoretical outcome of a battle is represented by the combat power 
ratio, $P_{r / b}: P_{b / r}$, in which the quality of the troops has not been considered. The actual outcome is presented by the result ratio, $R_{r / b}: R_{b / r}$. Dupuy then introduces the combat effectiveness value (CEV of a force to explain the difference between the theoretical and actual outcomes of a battle. Thus CEV would represent the "human factors" or "intangible behavioral considerations" present in the battle, such as leadership and morale. It is defined as

$$
C E V_{r / b}=\frac{R_{r / b} \times P_{b / r}}{R_{b / r} \times P_{r / b}}
$$

From this definition it follows immediately that

$$
C E V_{b / r}=\frac{1}{C E V_{r / b}} \text {. }
$$

However, Dupuy also defines $P_{r / b}$ and $P_{b / r}$ to be

$$
\begin{aligned}
& P_{r / b}=S_{r} \times V_{r} \times C E V_{r / b}, \\
& P_{b / r}=S_{b} \times V_{b} \times C E V_{b / r} .
\end{aligned}
$$

It follows from (1) to (3) that

$$
C E V_{r / b}=\left[\frac{R_{r / b} \times S_{b} \times V_{b}}{R_{b / r} \times S_{r} \times V_{r}}\right]^{\frac{1}{3}} \text {. }
$$

Formula (4) does not appear in Dupuy's work. It seems that he estimates values of CEV or sets it equal to values that he calculated or estimated previously for similar battles. This leads to deviations from the equations that we have derived above.

For example, in "Understanding War" [3], Dupuy analyses the 1940 Flanders campaign in the Second World War. In this example he states that the German CEV value relative to the Allies was 1.2. In his further calculations it seems that he then uses $C E V_{\text {German/Allies }}=1.2$ and $C E V_{\text {Allies/German }}=1.0$, which does not agree with the inverse relationship (2). On the other hand, if his statement means that $C E V_{\text {German/Alies }}: C E V_{\text {Allies/German }}=1.2$, then it follows from (2) that $C E V_{\text {German/Allies }}=1.0954$ and $C E V_{\text {Allies/German }}=0.9129$. 
An alternative interpretation of the calculation of CEV is that the preliminary values $C E V_{r / b}=1, C E V_{b / r}=1$ could be used to start the calculations. Since the values of $S$ and $V$ are calculated independently, equation (3) leads to values of $P_{r / b}$ and $P_{b / r}$ for the two sides. The results $R_{r / b}$ and $R_{b / r}$ are calculated independently from mission factors, spatial effectiveness and casualty effectiveness for each side. By using (1) a revised value of $C E V_{r / b}$ is then obtained, with the inverse relationship (2) providing the value of $C E V_{b / r}$. In this way (2) is automatically satisfied, but (4) is usually violated.

Consider for example the QJM analysis by W.J. Wagner and J.J.P. Erasmus [13] of the Battle of Talana, the first major battle of the Boer War [10, 12] of 18991902. In that early stage of the war the cooperation between the different elements of the Boer forces was poor and their planning was weak. A part of the Boer forces took up strong defensive positions on Talana and Lennox Hills near the town of Dundee. The well trained and better equipped British forces were ordered to safeguard the coal mines of Dundee. Although the British forces suffered more than double the number of casualties on the Boer side, they did succeed in driving the Boer forces from their positions. They did not, however, capitalise on this by follow-up operations. On the other hand the Boer forces missed an excellent opportunity to inflict a sensitive early blow on the British forces in Natal.

By using the alternative interpretation of the OJM calculations Wagner and Erasmus [13] find that

$$
\begin{array}{llll}
P_{\text {Boer/British }}=12691, & P_{\text {British/Boer }}=24271, \\
S_{\text {Boer }}=8056, & S_{\text {British }}=26916, \\
V_{\text {Boer }}=1.5753, & V_{\text {British }}=0.9017, \\
R_{\text {Boer/British }}=3.0000, & R_{\text {British/Boer }}=7.1578 .
\end{array}
$$

When these numbers are substituted in (4) they yield the value $C E V_{\text {Boer/British }}=$ 0.9289 , which does not agree with the value of 0.8016 that is obtained by 
Wagner and Erasmus by using the alternative interpretation of Dupuy's algorithm.

From this evidence it is clear that although the equations (2) and (4) are consequences of Dupuy's mathematical model, they are not necessarily satisfied by calculations with the QJM.

The intention of the definition (1) of the CEV is that it is a quotient which factors out the "human factors" present in the actual outcome from the theoretical outcome in which these factors were excluded. However, since the theoretical outcome in (3) already includes such factors by way of CEV, it appears that the definition in (1) confounds the issue.

We propose that the definitions

$$
P_{r}=S_{r} \times V_{r}, P_{b}=S_{b} \times V_{b}
$$

be introduced. Then define

$$
C E V_{r}=\frac{R_{r / b} \times P_{b}}{R_{b / r} \times P_{r}},
$$

where once again

$$
C E V_{b}=\frac{1}{C E V_{r}}
$$

From (5), (6) and (7) it follows that

$$
C E V_{r}=\frac{R_{r / b} \times S_{b} \times V_{b}}{R_{t / r} \times S_{r} \times V_{r}}
$$

In our opinion these results are mathematically more consistent and better achieve the stated purpose of separating out the human aspects of the battle.

For example, if the numbers mentioned above for the Battle of Talana are substituted in ( 8$)$, and (7) is also used, we obtain the values

$$
C E V_{\text {Boer }}=0.8016, C E V_{\text {British }}=1.2475,
$$


which agree with the values calculated by Wagner and Erasmus [13]. (There are minor numerical errors in their calculations.) Wagner and Erasmus interpret these values as indications that the British troops were better organized, trained and commanded than the Boer troops for this particular battle.

We emphasise that our analysis does not extend to the entire QJM. In particular, we have not attempted to evaluate the validity of the entire QJM according to standards that are used in operations research.

\section{A NEW SQUARE LAW}

Let $x$ and $y$ be the remaining number of units in the Red and Blue forces respectively after a time $t$ since the commencement of the battle. Assume that $x_{0}$ and $y_{0}$ are the respective values when $t=0$. With the two main assumptions of direct fire on specific targets and of the homogeneity of each force, the well-known Lanchester equations for attrition [11] are

$$
\frac{d x}{d t}=-a y, \quad \frac{d y}{d t}=-b x,
$$

where $a$ and $b$ are constant attrition coefficients. It is possible to attach operational meaning to these constants, for example in terms of weapon characteristics or the distribution of units in the battle terrain. It is also very important in the derivation of the equations that a unit should both be a firer and a target, so that both the destructive potential of a unit as well as its vulnerability are reflected in the equations. The solution of the equations (9) is the square law,

$$
a y^{2}-b x^{2}=a y_{0}^{2}-b x_{0}^{2} \text {. }
$$

Although the theory of Lanchester equations has developed tremendously [11], and even though they are often used in war games [5], there are serious doubts about the applicability of these equations to real battles $[5,8]$. Dupuy discusses some of these doubts in "Understanding War" [3] and proposes a variation that might be an improvement on the original equations. He defines an 


\section{1}

historical casualty-inflicting performance rate $K$ as the average daily casualties of a force, divided by $1 / 100$ th of the strength of the opposing side. Thus

$$
K_{r}=-\left(\frac{100}{x}\right) \frac{d y}{d t}, \quad K_{b}=-\left(\frac{100}{y}\right) \frac{d x}{d t} .
$$

He also introduces a posture factor $\mathrm{u}$ which is 1 for the attacking side and varies between 1.2 and 1.6 for the defending side. The lethality of a side is then defined as

$$
L=\frac{K}{u} .
$$

Lethality is considered to be the inherent casualty-inflicting capability of a force. On the basis of his QJM analyses Dupuy concludes that if Red is considered as the attacker, then

$$
K_{r}=\frac{K_{b}\left(C E V_{b}\right)^{-2}}{u_{b}}
$$

to a reasonable degree of approximation. By using (7) and (13) in (11) it follows that

$$
\begin{aligned}
& \frac{d x}{d t}=-0.01 u_{b} K_{r}\left(C E V_{b}\right)^{2} y, \\
& \frac{d y}{d t}=-0.01 \frac{K_{b}}{u_{b}}\left(C E V_{b}\right)^{-2} x .
\end{aligned}
$$

In conjunction with arguments that he uses in some of his other derivations, Dupuy now replaces the symbols $x$ and $y$ by the force strengths $S_{r}$ and $S_{b}$ respectively. In the case of heterogeneous forces these force strengths are obtained by weighting and aggregating the various components (artillery, infantry, armour, etc.) according to the methods of the QJM. The resulting equations,

$$
\begin{aligned}
& \frac{d S_{r}}{d t}=-0.01 u_{b} K_{r}\left(C E V_{b}\right)^{2} S_{b}, \\
& \frac{d S_{b}}{d t}=-0.01 \frac{K_{b}}{u_{b}}\left(C E V_{b}\right)^{-2} S_{r},
\end{aligned}
$$


are called the Lanchester quadratic equations with Dupuy coefficients, or the "new square law". In "Understanding War" [3] the replacement of numbers of units by force strengths is carried through only on the right hand side of equations (14). However, this leads to two differential equations in four unknowns, which would not be solvable in general. We therefore assume that (15) is the form that was intended. From a mathematical point of view the equations (15) have the same form as the original equations (9). In the new equations the variables are aggregated, and we can assume that new operational meanings have been attached to the coefficients. We now discuss the new square law.

In the first place we have serious doubts about the relationship (13) that Dupuy uses in his derivation of the new square law. Although this is not mentioned in "Understanding War", this relationship and the new square law were announced earlier in a paper by Dupuy at a Callaway Gardens Workshop of 1982 [2]. In this earlier paper the relationship is derived from data on 11 campaigns, but the accompanying graph shows 15 points. In "Understanding War" the relationship is derived from data on 15 campaigns, but the accompanying graph shows 11 points. The data refer to the same battles. In some instances the groupings of the battles differ, but even if this is taken into account there are differences in the two data sets. Exactly the same line is fitted through these different data sets, without any discussion of the norms that were used to fit the line. It is clear that this methodology cannot be accepted from a professional point of view in operations research. In the second place we note that the data in "Understanding War" sometimes contradict the ranges that were set for the variables. For example, in the Battle of the Bulge in the Second World War (item 10 of Tables $16-3$ and 16-4 of "Understanding War") we find for the Western Allies that $K=1.55$ and $L=0.54$, so that it follows from equation (12) that $u$ $=2.87$. However, this latter value is outside the previously mentioned range for posture factors. 
In the third place we cannot condone the way in which force strengths have been aggregated in equation (15). In their careful analyses of the intent of Lanchester's original equations, Lepingwell [8] and Homer-Dixon [6] point out the dangers involved in such aggregation. The main reasons for their concern are that the aggregated force strengths represent the destructive potential of weapons but do not incorporate any estimate of their vulnerability, and that the aggregation of heterogeneous forces violates the basic assumption of force homogeneity in the derivation of the Lanchester equations. One way which could be considered for the aggregation of heterogeneous forces is described by Howes and Thrall [7] and is applied in the war game IDAHEX [9].

In the fourth place equation (15b) apparently implies that the Blue force determines its own attrition coefficient, since the Red force has no influence on the rate per unit force strength at which it attrites the Blue force. This obvious contradiction is a weakness in Dupuy's variation of the Lanchester equations.

We mentioned previously that the alternative proposal in (5), which leads to the definition of CEV in (6), is in our opinion an improvement on the original definitions. However, our proposal is counterproductive with regard to Dupuy's new square law, since the empirically derived relation (13) on which the new square law is based does not necessarily hold for the CEV values in our proposal.

We have shown that Dupuy takes the original Lanchester equations as his point of departure, and that by the application of a number of transformations which cannot be defended on mathematical or practical grounds, he derives his new square law. We conclude that Dupuy has not provided a valid case for his new square law.

\section{ACKNOWLEDGEMENT}

We gratefully acknowledge the benefit that we have had of various discussions with W.J. Wagner on the QJM. In particular we are indebted to him for 
suggesting the use of the subscripts $b / r$ and $r / b$ in our notation. We are also grateful for his assistance in identifying minor numerical errors in his Q.JM analysis of the Battle of Talana [13]. However, the opinions expressed in this note are our own.

\section{REFERENCES}

[1] T.N. DUPUY. Numbers, Predictions, and War, Bobbs-Merrill, Indianopolis, New York (1979).

[2] T.N. DUPUY. Military history and simulation; with a focus on attrition, in Proceedings of the Workshop on Modeling and Simulation of Land Combat held at Callaway Gardens, Georgia, 28 - 31 March 1982, L.G. CALLAHAN, J.G. TAYLOR and F.E. GRUBBS. Eds., Georgia Tech Research Institute, Atlanta, 67 - 81 (1983).

[3] T.N. DUPUY. Understanding War: History and Theory of Combat, Paragon House Publishers, New York (1987).

[4] T.N. DUPUY. Attrition: Forecasting Battle Casualties and Equipment Losses in Modern War, Hero Books, Fairfax, Virginia (1990).

[5] J.M. EPSTEIN. The Calculus of Conventional War: Dynamic Analysis without Lanchester Theory, The Brookings Institution, Washington, D.C. (1985).

[6] T.F. HOMER-DIXON. A common misapplication of the Lanchester square law, International Security, 12(1), 135 - 139 (1987).

[7] D.R. HOWES, R.M. THRALL. A theory of ideal linear weights for heterogeneous combat forces, Naval Research Logistics Quarterly, 20(4), $645-659$ (1973).

[8] J.W.R. LEPINGWELL. The laws of combat? Lanchester re-examined, International Security, 12(1), 89 - 134 (1987).

[9] P. OLSEN, U. CANDAN, J.J. DE NIJS. IDAHEX Version 4, Volume 2 : Game Designer's Manual, SHAPE Technical Center Technical Memorandum STC TM-762, The Hague (1985). 
[10] T. PAKENHAM. The Boer War, Jonathan Ball Publishers, Cape Town (1979).

[11] J.G. TAYLOR. Lanchester Models of Warfare, Volumes I, II, Military Applications Section, Operations Research Society of America, Arlington, Virginia (1983).

[12] G. VAN LINGEN et al, Battlefields of South Africa, Jonathan Ball Publishers, Johannesburg (1991).

[13] W.J. WAGNER and J.J.P. ERASMUS. "Die Slag van Talana - 'n Krygskundige en kwantitatiewe evaluering," (The Battle of Talana - A military and quantitative evaluation), Militaria, 22(2), $17-24$ (1992). 